MARCIA TANJI

\title{
MERCADO DE CAPITAIS: \\ FORMAS DE ATUAÇÃO DO ESTADO
}

Tese apresentada à Banca Examinadora da Faculdade de Direito da Universidade de São Paulo, como exigência parcial para obtenção do título de Doutor em Direito, sob a orientação do Prof. Dr. Paulo Salvador Frontini.

FACULDADE DE DIREITO DA UNIVERSIDADE DE SÃO PAULO

SÃO PAULO

2013 


\section{RESUMO}

A observação do mercado de capitais brasileiro revela a constante presença do Estado: autoridade reguladora; acionista controlador de companhia aberta; sociedade de economia mista emissora de valores mobiliários; originador de ativos subjacentes a valores mobiliários; integrante do sistema de distribuição de valores mobiliários, por exemplo, bancos de investimento e corretoras sob controle estatal; cotista de fundo de investimento; entidade patrocinadora de fundos de pensão, os quais são relevantes investidores institucionais neste mercado. Os estudos sobre mercado de capitais focam a função regulatória estatal. Porém, outro aspecto merece ser abordado: o Estado não prescinde do mercado de capitais na implementação das políticas públicas. A atuação do Estado no processo econômico encontra fundamentos e limites na Constituição da República Federativa do Brasil. A exposição sistemática das formas de atuação do Estado pode contribuir para o controle que a sociedade deve realizar sobre a correção da atividade estatal e sobre a implementação das políticas públicas. Dessa forma, o objetivo do presente trabalho é sistematizar as diversas formas de atuação do Estado no mercado de capitais à luz de seus fundamentos constitucionais e legais e analisar de forma crítica as contradições, imprecisões, perspectivas e os desafios advindos da interação dinâmica entre as formas de atuação estatal.

Palavras-chave: Mercado de Capitais. Estado. Políticas Públicas. Regulação. Comissão de Valores Mobiliários - CVM. 


\begin{abstract}
An analysis of the Brazilian capital markets reveals the constant presence of the State in numerous capacities: regulatory authority; controlling shareholder of public companies; mixed-capital issuer of securities; originator of underlying assets for securities; participant in the security distribution system, such as through investment banks and brokers under state control; shareholder in investment funds; and sponsor of pension funds that are significant institutional investors in this market. Studies regarding the capital makets focus on the State's regulatory function. Another aspect, however, deserves to be addressed: the State does not leave aside the capital markets in the implementation of public policy. The actions of the State in the economic process has foundations and limits in the Constitution of the Federative Republic of Brazil. The systematic exposure of the forms of State action can contribute to the control that society should wield to correct State action and the implementation of public policy. In this sense, the objective of this work is to examine the various forms of State action in the capital markets in light of constitutional and legal foundations and analyze the contradictions, faults, perspectives and challenges arising from the dynamic interaction of such forms of action.
\end{abstract}

Keywords: Capital Markets. State. Public Policy. Regulation. Comissão de Valores Mobiliários - CVM. 


\section{RIASSUNTO}

L'osservazione del mercato dei capitali brasiliano rivela la presenza costante dello Stato: autorità di regolamentazione; azionista di controllo di società quotate in borsa; societá di economia mista emittente di valori mobiliari; originatore degli attivi sottostanti ai valori mobiliari; partecipante del sistema di distribuzione dei valori mobiliari, per esempio, banche di investimento e società de intermediazione su controllo statale; quotista nei fondi di investimenti; sponsor dei fondi di pensioni, che sono rilevanti investitori istituzionali di questo mercato. Gli studi sul mercato dei capitali mettono a fuoco la funzione di regolamentazione dello Stato. Tuttavia, un altro aspetto merita di essere affrontato: lo Stato non prescinde dal mercato dei capitali nell'applicazione delle politiche pubbliche. L'attuazione dello Stato nel processo economico trova i suoi fondamenti e limiti nella Costituzione della Repubblica Federativa del Brasile. L'esposizione sistematica delle forme di esecuzione dello Stato può contribuire per il controllo che la società deve realizzare sulla correzione dell'attività statale e sulla implementazione delle politiche pubbliche. Quindi, questo lavoro ha come obiettivo sistematizzare le diverse forme di prestazione dello Stato nel mercato dei capitali alla luce dei suoi fondamenti costituzionali e legali così come analizzare criticamente le contraddizioni, imprecisioni, prospettive e le sfide che hanno come origine la interazione dinamica fra le diverse forme di prestazione statale.

Parole-chiave: Mercato dei capitali. Stato. Politiche Pubbliche. Regolazione. Commissione dei Valori Mobiliari - CVM. 


\section{SUMÁRIO}

INTRODUÇÃO

CAPÍTULO I. A ATUAÇÃo DO ESTADO NO PROCESSO ECONÔMICO 16

1.1. Notas introdutórias

1.1.1. Poder Burocrático e Poder Econômico na Formação do Estado Moderno e nos Mercados .22

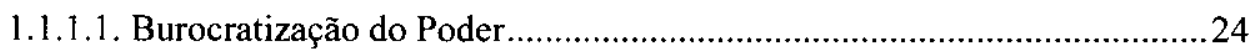

1.1.1.2. Crescente concentração do poder econômico..........................................36

1.1.2. A dupla instrumentalidade do direito e seus reflexos .........................................47

1.1.3. A nova concepção do direito comercial ...............................................................60

1.2. A atuação do Estado na Ordem Econômica e Financeira. A Constituição da República Federativa do Brasil de 1988 (CRFB)....................................................63

1.2.1. Classificação das formas de atuação do Estado no processo econômico..............64

1.2.1.1. Prestação de serviços públicos................................................................66

1.2.1.2. Atuação no domínio econômico ..............................................................68

1.2.1.3. Atuação sobre o domínio econômico .....................................................68

1.3. Regulação da atividade econômica: aspectos jurídicos ................................................68

1.4. Apontamentos sobre a evolução histórica da atuação estatal no processo econômico no Brasil

\section{CAPÍTULO II. MERCADO DE CAPITAIS BRASILEIRO} . .104

2.1. Notas introdutórias 104

2.2. A opção política: o Princípio do full disclosure .......................................................... 105

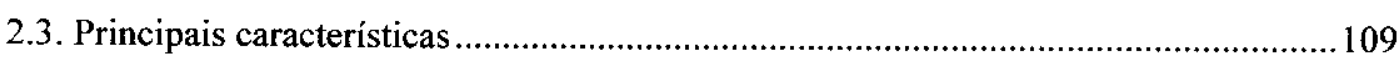

2.3.1. Função normativa atribuída ao Poder Executivo .............................................. 112

2.3.2. Indispensável integração entre Lei 6.385/1976 e Lei 6.404/1976 .................... 119

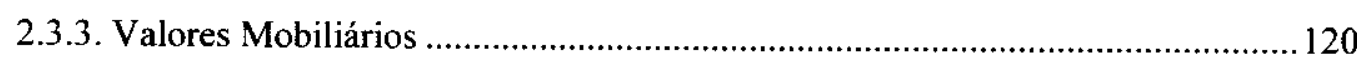

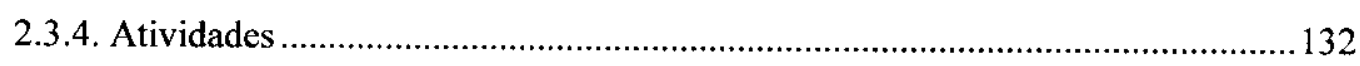

CAPÍtulo III. FORMAS de ATUAÇÃo do ESTADO NO MERCADO DE CAPITAIS BRASILEIRO: SISTEMATIZAÇÃO ................................136

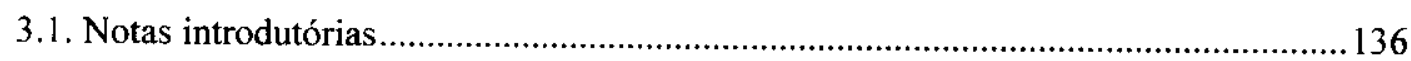

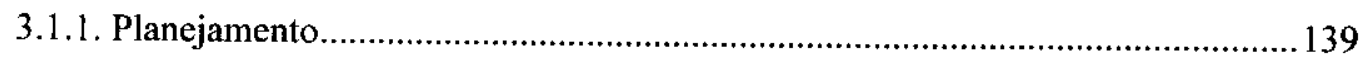

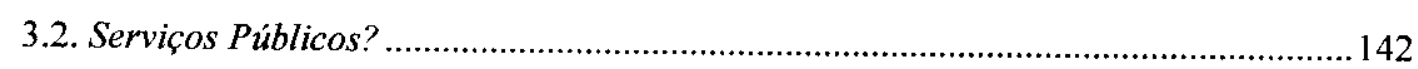

3.3. Atuação do Estado sobre o mercado de capitais ........................................................ 144

3.3.1. Por direção: regulação ................................................................................ 146 
3.1.1.1. Comissão de Valores Mobiliários.

3.1.1.1.1. Natureza jurídica.

3.1.1.1.2. Estrutura.

3.1.1.1.3. Funções .................................................................... 158

3.1.1.1.4. Principais instrumentos regulatórios................................... 162

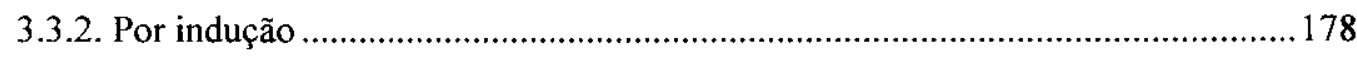

3.4. Atuação do Estado no mercado de capitais: agente econômico....................................185

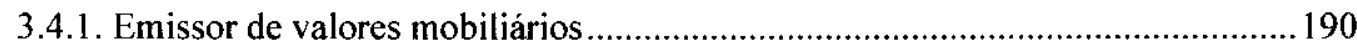

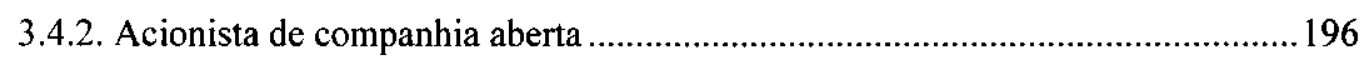

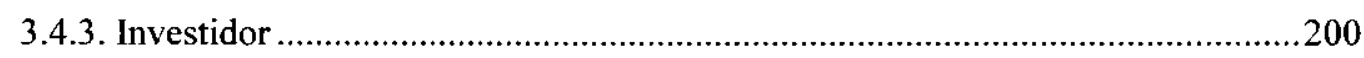

3.4.4. Originador de ativos subjacentes a valores mobiliários...................................201

3.4.5. Integrante do sistema de distribuição de valores mobiliários e prestador de demais atividades

\section{CAPÍTULO IV. FORMAS DE ATUAÇÃO DO ESTADO NO MERCADO DE CAPITAIS BRASILEIRO: PERSPECTIVA DINÂMICA ……………......206}

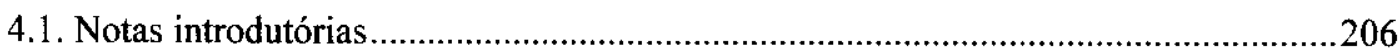

4.2. Atuação estatal sobre a atividade econômica em sentido lato: Diversidade de órgãos reguladores

4.2.1. Regulação setorial e mercado de capitais .......................................................208

4.2.2. Regulação transversal e mercado de capitais.....................................................208

4.3. Prestação de serviços públicos e exercício atividade econômica em sentido estrito pelo Estado e a regulação do mercado de capitais

4.4. Atuação do Estado sobre o mercado de capitais: diversidade de técnicas e diversidade de objetivos

4.5. Contradições e imprecisões da atuação do Estado. Perspectivas e desafios 


\section{INTRODUÇÃO}

A observação do mercado de capitais no Brasil revela a constante presença do Estado. Em uma análise da história recente, verifica-se que à época do processo de privatização, na última década do século passado, debateu-se intensamente a atuação do Estado na qualidade de agente econômico (o Estado-empresário).

A transformação da atuação estatal na prestação dos serviços públicos, especialmente nos setores de telecomunicações e energia elétrica; e na exploração direta de atividade econômica, especialmente nos setores de mineração e siderurgia; a alteração no regime de monopólio no setor petrolífero; o surgimento das agências reguladoras; bem como a gradativa incorporação de outros valores à conformação da atividade econômica (o meio ambiente, a defesa do consumidor, a livre concorrência, o público investidor) intensificaram o debate acerca do Estado agente normativo e regulador, seus fundamentos e limites, e a sua interação com a denominada "autorregulação". Pode-se afirmar que nos primeiros anos deste século prevaleceram estudos sob esta forma de atuação estatal no mercado de capitais.

Estes são os anos em que houve intenso desenvolvimento do mercado de capitais no país. Ilustram este cenário as alterações legislativas e as inovações trazidas pelos agentes econômicos ao mercado de capitais, a maior integração entre o mercado brasileiro e os mercados estrangeiros, e o aumento do volume de recursos objeto de negociação no mercado de capitais brasileiro ${ }^{1}$.

\footnotetext{
${ }^{1}$ Destaque para a ampliação do rol de valores mobiliários sujeitos ao regime da Lei 6.385/1976 advinda da reforma legislativa realizada em 2001. O número de ofertas públicas de ações, primárias e secundárias, e de operações de abertura de capital, registradas junto à Comissão de Valores Mobiliários (CVM), aumentou significativamente entre os anos de 2004 a 2008 e revela o aumento do volume de captação de recursos junto ao público investidor. $O$ aumento da captação de recursos para o financiamento das companhias foi acompanhado de aumento da participação de pessoas naturais no mercado de capitais e também de relevante incremento da presença dos investidores não-residentes, especialmente institucionais. Os efeitos da crise financeira internacional foram sentidos no mercado de capitais brasileiro, especialmente no mercado de derivativos, no segundo semestre de 2008 e início de 2009 (Cf. COMISSÃO DE VALORES MOBILIÁRIOS. Relatório Anual 2008. p. 3-6, e Relatório Anual 2009. p. 11-14. Disponível em: $<$ http://www.cvm.gov.br>. Acesso em: 09 jan. 2013; e BOLSA DE VALORES DE SÃO PAULO. Dados e notas Bovespa: abr/jun. 2008. Disponível em: <http://www.bmfbovespa.com.br/Pdf/dadosnotas.pdf>. Acesso em: 19. mar. 2013). Após o movimento de concentração das denominadas bolsas de valores regionais, as duas principais bolsas do país, de valores e de mercadorias e futuros, passaram a ser organizar sob a forma de sociedade anônima, abandonando a forma associativa, em alinhamento com movimento em curso em outros países, conhecido por "desmutualização das bolsas". Este processo foi seguido pela fusão das referidas principais bolsas, de valores e de mercadorias e futuros, ocorrida no ano de 2007 . Por fim
} 
Porém, o Produto Interno Bruto (PIB) verificado nos últimos anos e a declarada necessidade de vultosos investimentos em infraestrutura para o desenvolvimento econômico do País indicam a relevância de se incrementar a captação de recursos de longo prazo junto à poupança nacional e à estrangeira.

A participação do Estado na economia segue relevante no Brasil. A falta de clareza na exposição dos fundamentos da complexa alocação dos recursos públicos na economia não se restringe ao âmbito das obras públicas e contratos administrativos. Igualmente árdua é tarefa cometida ao cidadão na apreensão da versão de recursos públicos na atividade econômica em sentido estrito, seja sob a forma de empréstimo pelos bancos de desenvolvimento nacional e regionais, seja mediante a alocação desses recursos em participações acionárias.

De fato, há que se admitir a existência de maior divulgação de dados relativos à atuação do Estado decorrente do desenvolvimento do mercado de capitais no País. Uma das virtudes que o mercado de capitais pode espraiar a outras ordens é a exigência por transparência.

Porém, faz-se importante destacar que o princípio da transparência não se reduz à divulgação de informações. Pressupõe a simetria de informações, implica e requer o combate à concentração de poder econômico ${ }^{2}$.

Assim, verifica-se que a ausência de exposição clara, que se pressupõe completa, dessa forma de atuação do Estado na economia ao cidadão ${ }^{3}$ dificulta sobremaneira o

cumpre ressaltar a intensa integração entre os mercados nacional e estrangeiro e o avanço tecnológico empregado nas operações cursadas no mercado financeiro e de capitais na última década.

${ }^{2}$ Segundo Calixto Salomão Filho, a concentração de poder econômico encerra um dos maiores empecilhos à transmissão de informações e à troca comunicativa, por se qualificar como concentrador de conhecimento e informações e fator que origina e perpetua o desequilíbrio das relações econômicas e da distribuição de renda, ao impedir que a parte sem poder adquira informação ou conhecimento. $O$ autor propugna por uma teoria econômica procedimental, "[...] cujo objetivo é criar condições de um devido processo econômico, permitindo a inclusão mais ampla possível e a formação própria de escolhas pelos agentes econômicos, com o nível de informações mais equilibrado possível" (Cf. SALOMÃO FILHO, Calixto. Poder Econômico: a marcha da aceitação. In: COMPARATO, Fábio Konder; SALOMÃO FILHO, Calixto. $O$ Poder de Controle na Sociedade Anonima, p. 21-23).

${ }^{3}$ Este cenário inexoravelmente leva ao cidadão a sensação de ser um acionista minoritário a quem se dificulta ou nega acesso à informação em uma sociedade denominada "Brasil S/A" ou "Estado Ltda.". Esta última expressão foi título da reportagem de José Fucs e Marcos Coronato, intitulada "Estado Ltda.", publicada na Revista Época $\mathrm{n}^{\circ}$ 682, em 13 de junho de 2011, p. 64-70. Uma equipe integrada pelos mencionados jornalistas e por Keila Cândido, Matheus Paggi, Camila Camilo, Danilo Thomaz e Juliana Elias, anatisou dados divulgados pela empresa de informações financeiras Economática, pelo governo federal, pela BM\&FBovespa e pelas empresas para apreender a situação atual da intervenção do governo federal na economia do país e tentar responder à seguinte questão: o que exatamente faz o governo num país de economia complexa como o Brasil? Os autores afirmam a existência de 675 empresas em todos os setores com algum tipo de participação ou influência do governo federal (participações diretas ou indiretas do 
controle que a população deve realizar sobre correção da atividade estatal e sobre a implementação das políticas públicas ${ }^{4}$.

Observe-se que o debate se faz forte, mas não sobre bases mais claras, nas instâncias de representação popular. Discute-se a alocação de recursos públicos na economia de forma episódica e sempre no ápice da possibilidade da concreção deste ou daquele investimento pelo Estado em determinada companhia ou setor da economia, mas não há uma chamada à discussão profunda que construa bases de consenso a permitir o planejamento dessa forma de atuação estatal a longo prazo e o exercício de controle mais efetivo pelas próprias instâncias de representação do povo.

Sendo assim, a sistematização das formas de atuação do Estado e a análise dinâmica da interação entre essas formas e da relação entre Estado e agentes econômicos pode contribuir para o contraste entre o que se realiza na atualidade e o papel reservado ao Estado conforme as normas constitucionais e legais vigentes. A partir desta análise, buscar-se-á a identificação de disfunções e de funções negativas no sistema ${ }^{5}$, sempre sob a perspectiva do mercado de capitais brasileiro, com o objetivo de pensar propostas à sua solução.

Para tanto, parte-se da análise da atuação do Estado no processo econômico. $O$ primeiro capítulo trata da conformação do Estado Liberal, erigido da Revolução Francesa e da Revolução Americana, e da passagem a um estado de coisas completamente novo que se apresenta com o advento da Revolução Industrial, recorrendo-se aos grandes pensamentos e ao instrumental teórico, talhados para compreender os homens e a sociedade, os indivíduos e os grupos.

Tesouro Nacional, dos bancos e empresas estatais e dos fundos de pensão), entre as quais 276 sob controle do governo. Os jornalistas concluem que se o governo concentrasse a atuação nos setores de educação, saúde e segurança, diminuindo sua face Estado-empresário, haveria menos corrupção, tráfico de influência e apadrinhamento. Por fim, defendem os autores que o governo federal concentre seus esforços na fiscalização e na regulação do mercado, para garantir qualidade e boa prestação de serviços à população.

$\mathrm{O}$ artigo mencionado parte do conhecido debate do papel do Estado na economia, explorado anteriormente. Independentemente da posição que se adote a este respeito - que certamente determinará a eleição de alguns dos critérios a serem empregados na investigação -, o que se extrai da reportagem é a percepção da relevância de se identificar, com clareza, a participação do Estado na economia. Outrossim, independentemente da posição que se adote acerca do cenário atual da política no país, o artigo revela disfunções importantes que podem surgir na atuação do Estado na economia, as quais merecem ser estudadas na busca por soluções.

${ }^{4}$ Este aspecto foi destacado por Diogo de Figueiredo Moreira Neto: "Como se observa, para a imposição da intervenção necessita-se do Estado, como titular do monopólio da força e como agente imparcial, para exercer esta atividade, mas necessita-se também do concurso da sociedade, para legitimá-la e para definir, em cada tempo histórico, em cada país e em cada setor, o que seja a intervenção suficiente" (MOREIRA NETO, Diogo de Figueiredo. Direito regulatório. Rio de Janeiro: Renovar, 2003. p. 78).

${ }^{5} \mathrm{Cf}$. BOBBIO, Norberto. Da estrutura à função: novos estudos de teoria do direito. Trad. de Daniela Beccaccia Versiani; rev. téc. de Orlando Seixas Bechara, Renata Nagamine. São Paulo: Manole, 2007. 
Há que se recordar que o objeto do estudo é o mercado de capitais. Evitando a dispersão neste fascinante mundo, busca-se o norte nas sempre percucientes palavras de Fábio Konder Comparato: não descurar o poder ${ }^{6}$. Passa-se à análise do fenômeno da burocratização do poder e da crescente concentração de poder econômico, a qual permeará todo o percurso do trabalho.

À luz da compreensão de que as trocas econômicas no modo de produção capitalista são sempre jurídicas, observa-se o direito, condição específica que confere fluência à circulação mercantil ${ }^{7}$, e os reflexos sob sua estrutura e função decorrentes das profundas transformações ocorridas desde o século XVIII. Releva, particularmente, a percepção da dupla instrumentalidade do direito e de seus reflexos, entre os quais os desafios lançados pela tendência de ampliação do exercício de função normativa pelo Poder Executivo. A observação dos consectários da adoção das políticas públicas como moto legitimador do Estado de Direito Social favorece a apreensão dos desafios com os quais se defronta aquele que pretende estudar o direito na atualidade ${ }^{8}$, especialmente no que tange ao Direito Comercial $^{9}$.

Trata-se a seguir das formas de atuação do Estado no processo econômico à luz da Constituição da República Federativa do Brasil (CRFB). Para tanto, recorre-se à classificação lavrada por Eros Roberto Grau, cuja adoção se mostra adequada à análise ora proposta, uma vez que, conforme explica o autor, a dinamização de cada modalidade de intervenção identificada envolve critérios e técnicas que se distinguem, entre si, juridicamente ${ }^{10}$.

Recorre-se à doutrina pátria, na tentativa de extrair os contornos de uma teoria jurídica de regulação da atividade econômica. A função e a atividade reguladoras (ou regulatórias) passam ao centro da investigação, na tentativa de aferir suas condicionantes, seus limites e seu caráter específico.

${ }^{6}$ COMPARATO, Fábio Konder; SALOMÃO FILHO, Calixto. O poder de controle na sociedade anônima. 4. ed. Rio de Janeiro: Forense, 2005. p. XV-XVII.

${ }^{7}$ Cf. GRAU, Eros Roberto. O direito posto e o direito pressuposto. 8. rev. ampl. São Paulo: Malheiros Ed., 2011. p. 58

${ }^{8} \mathrm{Cf}$. COMPARATO, Fabio Konder. Ensaio sobre o juízo de constitucionalidade de políticas públicas. Interesse Público, Belo Horizonte, v. 4, n. 16, out. 2002. Disponível em: $<$ http://bdjur.stj.jus.br/dspace/handle/2011/31244>. Acesso em: 05 dez. 2012.

${ }^{9} \mathrm{Cf}$. FORGIONI, Paula A. A evolução do direito comercial brasileiro: da mercancia ao mercado. 2 . ed. rev. atual. ampl. São Paulo: Ed. Revista dos Tribunais, 2012. p. 153-195.

${ }^{10} \mathrm{Cf}$. GRAU, Eros Roberto. A Ordem Económica na Constituição de 1988. 14. ed. rev. atual. São Paulo: Malheiros Ed., 2010. p. 90-153. 
Finalmente, breves linhas são dedicadas à evolução histórica da atuação estatal no processo econômico no Brasil, tratando com mais vagar e minudência das transformações atinentes ao mercado de capitais, objeto do presente trabalho.

O segundo capítulo foi dedicado ao mercado de capitais brasileiro, palco das formas de atuação estatal que se pretende apreender. Apresenta-se a estrutura normativa atual do mercado de capitais brasileiro, o norte que este extraiu da opção política realizada, e suas principais características. Os valores mobiliários mereceram atenção redobrada. Recorreu-se ao pensamento de Tullio Ascarelli ${ }^{11}$ acerca da distinção entre os conceitos jurídicos na interpretação do direito, em uma tentativa de compreender a função que este conceito desempenha no mercado de capitais brasileiro.

No terceiro capítulo realiza-se a sistematização das formas de atuação do Estado no mercado de capitais brasileiro. Partindo da observação da constante presença do Estado neste âmbito, sob distintas formas (por exemplo: autoridade reguladora; acionista controlador de companhia aberta; sociedade de economia mista emissora de valores mobiliários; originador de ativos subjacentes a valores mobiliários; integrante do sistema de distribuição de valores mobiliários, por exemplo, bancos de investimento e corretoras sob controle estatal; cotista de fundo de investimento; entidade patrocinadora de fundos de pensão, relevantes investidores institucionais neste mercado), busca-se apartá-las, à luz da classificação das formas de atuação do Estado no processo econômico lavrada por Eros Roberto Grau.

A análise se desenvolve sob uma perspectiva estática, propositadamente adotada; recurso necessário a que se possa bem vincar os fundamentos constitucionais e legais de cada forma de atuação estatal. Sob o ponto de vista metodológico, tal sistematização é necessária à análise da interação entre as diversas formas de atuação estatal e das relações travadas entre Estado e agentes econômicos no mercado de capitais a ser realizada no quarto capítulo. Porém, também se apresenta como contribuição na empreitada de propiciar mecanismos ao controle da correção da atividade estatal e da implementação das políticas públicas.

No quarto capítulo, a atuação do Estado no mercado de capitais brasileiro é objeto de análise sob a perspectiva da dinâmica da interação entre suas diversas formas e

\footnotetext{
${ }^{11}$ ASCARELLI, Tullio. Studi di diritto comparato e in tema di interpretazione. Milano: Giuffrè, 1952. p. XIV-XV. E também COMPARATO, Fábio Konder; SALOMÃO FILHO, Calixto. op. cit., p. 334-338; e GRAU, Eros Roberto. op. cit., p. 196-197.
} 
das distintas relações que o Estado trava com os agentes econômicos, com o objetivo de extrair suas contradições e imprecisões, e apresentar, afinal, perspectivas e desafios.

O trabalho se encerra com a apresentação das notas conclusivas. 


\section{NOTAS CONCLUSIVAS}

"Estado" está a significar uma plêiade de pessoas jurídica de direito público, pessoas jurídicas de direito privado, entes despersonalizados (fundos), atuantes em diversos setores, com diversos objetos sociais, sob diversos regimes jurídicos, em busca da consecução de diversas finalidades.

Ao atuar no mercado de capitais sob as diversas formas previstas no ordenamento jurídico, o Estado assim o faz para encetar não somente a regulação deste específico mercado. Atua com vistas à regulação setorial de outro campo (petróleo, telecomunicações, elétrico); à captação de recursos junto à poupança popular para o desenvolvimento da infraestrutura necessária à prestação de serviços públicos e para o crescimento do setor produtivo privado; à utilização dos instrumentos de mercado destinados à administração dos mais diversos riscos para o atendimento de metas de politica econômica e de política fiscal; à consecução dos objetivos caros à previdência (entidade fechadas de previdência complementar, os fundos de pensão).

Observa-se, assim, que o Estado busca sua legitimidade na implementação das políticas públicas e, para tanto, não prescinde do mercado de capitais, o qual recebe o constante e dinâmico influxo da atuação estatal. A CRFB, em seu art. 174, dispôs acerca de uma essencial qualidade a ser conferida à atividade econômica em sentido lato: o planejamento, obrigatório para o setor público e facultativo para o setor privado; apto a influenciar não somente no agir da Administração Pública, mas também no setor privado, a conferir racionalidade e a previsibilidade, elementos caros ao processo econômico.

A ausência de clareza na exposição da atuação do Estado na economia dificulta sobremaneira o controle que a população deve realizar sobre correção da atividade estatal, pois foi atribuída ao planejamento a tarefa de conferir consistência racional à atuação estatal, ao formular os objetivos e diretrizes das políticas públicas a serem implementadas $^{421}$. Acrescente-se que ao planejamento também foi conferida importante

\footnotetext{
${ }^{421}$ Nos dizeres de Fábio Konder Comparato: "Como toda organização de poder, o Estado define-se pela estrutura interna dos seus órgãos e pela determinação das finalidades ou funçð̃es a serem exercidas" (Cf. Rumo à Justiça, p. 301). O autor ressalta que para garantir minimamente a consecução dos objetivos previstos no art. $3^{\circ}$ da CRFB mostra-se indispensável reorganizar a estrutura estatal, com a criação de um órgão autônomo de planejamento, nas esferas federal, regionais (art. 43 da CRFB) e metropolitanas (art. 25, $\S 3^{\circ}$, da CRFB), ao qual seria atribuida competência exclusiva para a elaboração de planos de desenvolvimento, programas sociais e orçamentos plurianuais. Mais que isso, propõe o autor a participação do povo em plebiscito para aprovação de suas diretrizes, seguidas da decisão final do órgão parlamentar
} 
função no que tange à relação entre as diversas formas de atuação estatal em sua dinâmica e a atuação dos agentes econômicos: é a medida imposta pela CRFB, a ser aferida a cada momento, para o equilibrio entre atuação estatal e autonomia privada.

A interação da sociedade com o agir estatal faz-se imprescindível no planejamento $^{422}$ e na formulação das políticas públicas; na formulação de planos destinados a setores específicos do processo econômico, identificado como sensiveis, entre os quais o mercado de capitais (regulação da atividade econômica) ${ }^{423}$; bem como na formatação do interesse público específico no âmbito da empresa estatal ${ }^{424}$. Identifica-se, assim, a importância da formulação de arranjos institucionais e mecanismos voltados à mencionada interação, para o que o direito desempenha papel relevante.

A concepção da imprescindibilidade da interação entre sociedade e agir estatal advém do reconhecimento de que a regulação da atividade econômica - expressão aqui necessariamente adotada em seu sentido lato - não se volta ao atingimento de um resultado ótimo predeterminado, mas sim à criação de canais de transmissão do conhecimento econômico adquirido de forma difusa na sociedade e das condições para um devido processo econômico $^{425}$, garantia institucional da correção e do equilíbrio deste processo, por meio da inclusão mais ampla possível (acesso) e de nível de informações mais equilibrado possível, a permitir a formação própria de escolhas pelos agentes econômicos.

A interação entre sociedade e agir estatal na regulação da atividade econômica por meio de formas democráticas é apta a revelar a definição de objetivos valorizados, e a integrar às formas de atuação estatal no processo econômico e, assim, no mercado de capitais, a proteção de outros valores constitucionalmente previstos, como o meio ambiente e o desenvolvimento equilibrado do País.

competente, bem como a criação de um Conselho para atuar no referido órgão, que contaria com a participação de setores importantes da sociedade civil (empresários, trabalhadores, pesquisadores, conselheiros populares, entre outros).

${ }^{422}$ COMPARATO, Fábio Konder. Rumo à justiça, cit., p. 301.

${ }^{423}$ MOREIRA NETO, Diogo de Figueiredo. op. cit., p. 155-158.

${ }^{424}$ PINTO JUNIOR, Mario Engler. op. cit., p. $245 ; 347$.

${ }^{425}$ SALOMÃO FILHO, Calixto. Poder econômico: a marcha da aceitação, cit., p. 21-23; Regulação e desenvolvimento: novos temas, cit., p. 9-69. 


\section{REFERÊNCIAS}

ADAMEK, Marcelo von. Responsabilidade civil dos administradores de $S / A$ e as ações correlatas. São Paulo: Saraiva, 2010.

ADVOCACIA-GERAL DA UNIÃO. Parecer n. AGU/LA-01/2001. Disponível em: $<$ http://www.agu.gov.br>. Acesso em: 09 jan. 2013.

AKERLOF, G. The market for lemons: qualitative uncertainty and the market mechanism. Quarterly Journal of Economics, v. 84, n. 3, 1970.

ANDREZO, Andréa Fernandes; LIMA, Iran Siqueira. Mercado financeiro: aspectos históricos e conceituais. São Paulo: Pioneira, 2001.

ARAGÃO, Alexandre Santos de. Agências reguladoras e a evolução do direito administrativo econômico. 2 ed. Rio de Janeiro: Forense, 2004.

- A concepção pós-positivista do princípio da legalidade. Revista de Direito Administrativo, Rio de Janeiro, n. 236, p. 51-64, abr./jun. 2004.

. Curso de direito administrativo. Rio de Janeiro: Forense, 2012.

A legitimação democrática das agências reguladoras. In: BINENBOJM, Gustavo (Coord.). Agências reguladoras e democracia. Rio de Janeiro: Lumen Juris, 2006. p. 1-20.

ARENDT, Hannah. Sobre a violência. Trad. de André Duarte. Rio de Janeiro: Civilização Brasileira, 2009.

ASCARELLI, Tullio. Panorama do direito comercial. São Paulo: Saraiva, 1947.

- Problemas das sociedades anônimas e direito comparado. 1. ed. São Paulo: Saraiva, 1945.

. Studi di diritto comparato e in tema di interpretazione. Milano: Giuffrè, 1952.

ASQUINI, Alberto. Perfis da empresa. Tradução de Fábio K. Comparato. Revista de Direito Mercantil, Industrial, Econômico e Financeiro, São Paulo, nova série, v. 35, n. 104, p. 109-126, out./dez. 1996. 
ÁVILA, Humberto. Teoria dos princípios: da definição à aplicação dos princípios jurídicos. 12. ed. ampl. São Paulo: Malheiros Ed., 2011.

BALASSIANO, Luis Alberto Lichtenstein. Efetividade das sanções pecuniárias impostas por entidades reguladoras: o protesto extrajudicial da dívida ativa. 2012: Trabalho de Conclusão de Curso (Pós-graduação em Direito do Estado e da Regulação). Escola de Direito do Rio de Janeiro - FGV DIREITO RIO - Fundação Getúlio Vargas, 2012.

BANCO CENTRAL DO BRASIL. COMISSÃO DE VALORES MOBILIÁRIOS. Convênio de 28 out. 2010. Disponível em: <http://www.cvm.gov.b>. Acesso em: 09 jan. 2013.

BANDEIRA DE MELLO, Celso Antonio. Curso de direito administrativo. 21. ed. rev. e atual. até a Emenda Constitucional 52, de 8.3.2006. São Paulo: Malheiros Ed., 2006.

BECKER, Alfredo Augusto. Teoria geral do direito tributário. 5. ed. São Paulo: Noeses, 2010.

BERCOVICI, Gilberto. O ainda indispensável direito econômico. In: BENEVIDES, Maria Victoria de Mesquita; BERCOVICI, Gilberto; MELO, Claudinei de (Orgs.). Direitos humanos, democracia e república: homenagem a Fábio Konder Comparato. São Paulo: Quartier Latin, 2009. p. 503-519.

BERLE JR, A. A.; MEANS, G. The modern corporation and private property. New York: Harcourt, Brace \& World, 1967.

BLACK, Bernard S. The legal and institutional preconditions for strong securities markets. UCLA Law Review, v. 48, p. 781-855, 2001. Disponivel em: $<\mathrm{http}: / /$ ssrn.com/abstract=182169>. Acesso em: 10 abr. 2005.

BNDES PARTICIPAÇÕES S/A - BNDESPAR. Estatuto Social. Disponível em http://www.bndes.gov.br/SiteBNDES/bndes/bndes_pt/Institucional/O_BNDES/Legislacao/ estatuto bndespar.html. Acesso em 25 mar. 2013.

. Strengthening Brazil's securities markets. Stanford Law School, 2000. Disponível em: <http:/www.papers.ssrn.com/papers.taf?abstract_id=247673>. Acesso em: 10 abr. 2005 .

BOBBIO, Norberto. Da estrutura à função: novos estudos de teoria do direito. Trad. de Daniela Beccaccia Versiani; rev. téc. de Orlando Seixas Bechara, Renata Nagamine. São Paulo: Manole, 2007. 
. Em direção a uma teoria funcionalista do direito. In: Da estrutura à

função: novos estudos de teoria do direito. Trad. de Daniela Beccaccia Versiani; rev. téc. de Orlando Seixas Bechara, Renata Nagamine. São Paulo: Manole, 2007.

Direito e ciências sociais. In: . Da estrutura à função: novos estudos de teoria do direito. Trad. de Daniela Beccaccia Versiani; rev. téc. de Orlando Seixas Bechara, Renata Nagamine. São Paulo: Manole, 2007.

Estrutura e função na teoria do direito de Kelsen. In: Da estrutura à função: novos estudos de teoria do direito. Trad. de Daniela Beccaccia Versiani; rev. téc. de Orlando Seixas Bechara, Renata Nagamine. São Paulo: Manole, 2007.

A função promocional do direito. In: Da estrutura à função: novos estudos de teoria do direito. Trad. de Daniela Beccaccia Versiani; rev. téc. de Orlando Seixas Bechara, Renata Nagamine. São Paulo: Manole, 2007.

Kelsen e o problema do poder. Kelsen e o poder jurídico. Max Weber e Hans Kelsen. In: . Direito e poder. Trad. de Nilson Moulin. São Paulo: UNESP, 2008.

Teoria do ordenamento juridico. Tradução de Maria Celeste Cordeiro Leite dos Santos. 7. ed. Brasília: Universidade de Brasília, 1996.

BOLSA DE VALORES DE SÃO PAULO. Dados e notas Bovespa: abr./jun. 2008. Disponível em: <http://www.bmfbovespa.com.br/Pdf/dadosnotas.pdf $>$. Acesso em: 19. mar. 2013.

BONELLI, Regis; PINHEIRO, Armando Castellar. O Papel da poupança compulsória no financiamento do desenvolvimento: desafios para o BNDES. Revista do BNDES, Rio de Janeiro, v. 1, n. 1, p. 17-36, jun. 1994. Disponível em: <www.bndes.gov.br>. Acesso em: 09 jan. 2013.

CARVALHOSA, Modesto; EIZIRIK, Nelson Lakz. A nova Lei das S/A. São Paulo: Saraiva, 2002.

CEREZETTI, Sheila Christina Neder. Administradores Independentes e Independência dos Administradores (Regras Societárias Fundamentais ao Estímulo do Mercado de Capitais Brasileiro). In: ADAMEK, Marcelo Vieira von (coord.). Temas de Direito Societário e Empresarial Contemporâneos. São Paulo: Malheiros, 2011, p. 571-593. 
Regulação do mercado de capitais e desenvolvimento. In: SALOMÃO FILHO, Calixto (Coord.). Regulação e desenvolvimento: novos temas. São Paulo: Malheiros Ed., 2012. p. 190-228.

CINTRA, Antonio Carlos de Araújo; DINAMARCO, Cândido R.; GRINOVER, Ada Pellegrini. Teoria geral do processo. 13. ed. rev. atual. São Paulo: Malheiros Ed., 1997.

COFFEE, John C.; SELIGMAN, Joel; SALE, Hillary A. Securities regulation: cases and materials. 10th ed. New York: Foundation Press, 2007.

COMISSÃO DE VALORES MOBILIÁRIOS. Ata da Reunião Extraordinária do Colegiado de 28. dez. 2012. Disponível em: <http://www.cvm.gov.br>.

. Ata da sessão de julgamento. PAS TA-RJ2001/11949. Disponível em: <http://www.cvm.gov.br>. Acesso em: 20 jan. 2013.

. Convênios. Disponível em: <http://www.cvm.gov.br>. Acesso em: 20 jan. 2013.

. Decisão do Colegiado: PA CVM RJ2003/0499. Disponível em: $<$ http://www.cvm.gov.br>.

Decisão do Colegiado. Processo Administrativo RJ 2005/0739. Disponível em: $<$ http://www.cvm.gov.br>. Acesso em: 09 jan. 2013.

. Disponível em: <http://www.cvm.gov.br>. Acesso em: 19 jul. 2011.

. Edital de Audiência Pública 01/2013. Disponível em: <http://www.cvm.gov.br>. Acesso em: 12 fev. 2013.

Extrato da Ata da Sessão de Julgamento do processo administrativo sancionador CVM No RJ2009/4768. Disponível em: <http://www.cvm.gov.br>. Acesso em: 05 jan. 2013.

- Extrato da Sessão de Julgamento de 14/12/2010. Disponível em: $<$ http://www.cvm.gov.br>.

. Extrato da Ata da Sessão de Julgamento do processo administrativo sancionador CVM No RJ2009/4768. Disponível em: <http://www.cvm.gov.br>. Acesso em: 05 jan. 2013. 
. Extrato de sessão de julgamento: Processos Administrativos Sancionadores IA ${ }^{\circ}$ 17/01, TA n ${ }^{\circ}$ 6094/01 e TA n ${ }^{\circ} 3535 / 02$. Disponível em: <http:/www.cvm.gov.br>. Acesso em: 15 ago. 2005.

- Extrato de Reunião do Colegiado da CVM 34/12. Disponível em: $<\mathrm{http}: / /$ www.cvm.gov.br $>$.

- Nota explicativa à Instrução CVM 475/2008. Disponível em: $<$ http://www.cvm.gov.br $>$.

- Nota explicativa à Instrução CVM 308/1999. Disponível em: <http:/www.cvm.gov.br>. Acesso em: 09. jan. 2013.

. Nota explicativa da Instrução CVM $\mathrm{n}^{\circ}$ 92/1988. Disponível em: <www.cvm.gov.br>. Acesso em: 09 jan. 2013.

Parecer de Orientação CVM 19/90. Disponivel em: <http://www.cvm.gov.br>. Acesso em: 15 mar. 2013.

- Parecer do Comitê de Termo de Compromisso ao Processo Administrativo Sancionador 16/2008, 28 ago. 2012. Disponível em: <http:/www.cvm.gov.br $>$.

$\begin{array}{llll}\text { <http://www.cvm.gov.br>. } & \text { RACVM/SEP/GEA-3/n } & \text { 102/12, de 30.11.12. Disponivel em: }\end{array}$ . Regulação do mercado de valores mobiliários: fundamento e princípios. Rio de Janeiro, 1979.

. Relatório Anual 2008. Disponível em: <http://www.cvm.gov.br >. Acesso em: 09 jan. 2013. jan. 2013.

Relatório Anual 2009. Disponível em: <http://www.cvm.gov.br>. Acesso em: 09

Relatório Anual 2011. Disponível em: <http://www.cvm.gov.br>. Acesso em: 20 jan. 2013.

- Relatório de Audiência Pública $\mathrm{n}^{\circ}$ 01/11. Disponível em: $<$ http://www.cvm.gov.br>.

. Relatórios Anuais 2008 a 2011. Disponível em: <http:/www.cvm.gov.br>. 
Superintendência de Relações com Empresas. OFÍCIOCIRCULAR/CVM/SEP/N ${ }^{\circ}$ 01/2013. Disponível em: <http://www.cvm.gov.br>. Acesso em: 15 mar. 20.

COMPANHIA DE SANEAMENTO AMBIENTAL DO DISTRITO FEDERAL CAESB. Prospecto de Oferta Pública. Disponível em: $<$ http:/www.caesb.df.gov.br/images/arquivos pdf/CAESBDEFPRINT.pdf $>$. Acesso em 09 jan. 2013.

COMPARATO, Fabio Konder. As ações de sociedade anônima como valores mobiliários: natureza e efeitos do registro acionário. In: . Novos ensaios e pareceres de direito empresarial. Rio de Janeiro: Forense, 1981.

Ensaio sobre o juízo de constitucionalidade de políticas públicas. Interesse Público, Belo Horizonte, v. 4, n. 16, out. 2002. Disponível em: $<$ http://bdjur.stj.jus.br/dspace/handle/2011/31244>. Acesso em: 05 dez. 2012.

. Ensaios e pareceres de direito empresarial. Rio de Janeiro: Forense, 1978.

. Estado, empresa e função social. Revista dos Tribunais, São Paulo, v. 85, n. 732 , p. $38-46$, out. 1996 .

. O indispensável direito econômico. In: . Ensaios e pareceres de direito empresarial. Rio de Janeiro: Forense, 1978.

. Novos ensaios e pareceres de direito empresarial. Rio de Janeiro: Forense, 1981.

. Ordem Econômica na Constituição brasileira de 1988. Revista de Direito Público, São Paulo, ano 23, n. 93, p. 263-276, 1990.

. A regra do sigilo nas ofertas públicas de aquisição de ações. In: . Direito empresarial: estudos e pareceres. São Paulo: Saraiva, 1990.

. Rumo à justiça. São Paulo: Saraiva Jurídico, 2010.

- Sociedade de economia mista transformada em sociedade anônima ordinária inconstitucionalidade. Revista Trimestral de Direito Público, São Paulo, n. 25, p. 61-68, 1999

; SALOMÃO FILHO, Calixto. O poder de controle na sociedade anônima. 4. ed. Rio de Janeiro: Forense, 2005. 
COX, James D.; HILLMAN, Robert W.; LANGEVOORT, Donald C. Securities regulation: cases and materials. 4. ed. New York: Aspen Publishers, 2004.

CROZIER, Michel. Relações de poder e situação de incerteza: o sistema de organização burocrática. In: . O fenômeno burocrático: ensaio sobre as tendências burocráticas dos sistemas de organização modernos e suas relações, na França, com o sistema social e cultural. Trad. de Juan A. Gili Sobrinho, Brasília: Universidade de Brasília, 1981. p. 211 303 .

DE LUCCA, Newton. Regime juridico da empresa estatal no Brasil. Tese (Livre Docência) - Faculdade de Direito, Universidade de São Paulo, São Paulo, São Paulo, 1986.

DIAS, Luciana Pires. Regulação e auto-regulação no mercado de valores mobiliários. 2005. Dissertação (Mestrado) - Faculdade de Direito, Universidade de São Paulo, São Paulo: 2005.

DUARTE, Soraia de Oliveira. Governança corporativa, mercado de capitais $e$ desenvolvimento económico: estudos de caso dos Fundos de Pensão e Previdência do Brasil, Chile e México. 2011. Dissertação (Mestrado) - Programa de Pós-Graduação em Integração Latino-Americana, Universidade de São Paulo, São Paulo, 2011.

DUBEUX, Julio Ramalho. A comissão de valores mobiliários e os principais instrumentos regulatórios do mercado de capitais brasileiro. Porto Alegre: Sergio Antonio Fabris, 2006.

DUTRA, Marcos Galileu Lorena. As novas estruturas organizacionais das bolsas. 2008. Tese (Doutorado) - Faculdade de Direito, Universidade de São Paulo, São Paulo, 2008.

EIZIRIK, Nelson. Aspectos modernos do direito societário. Rio de Janeiro: Renovar, 1992.

O Estado como acionista controlador de companhias integrantes do mercado acionário - o "Caso Vale". In: Questões de direito societário e de mercado de capitais. Rio de Janeiro: Forense, 1987.

O papel do Estado na regulação do mercado de capitais. Rio de Janeiro: IBMEC, 1977. (Série Estudos Especiais n. 3).

1987.

Questões de direito societário e mercado de capitais. Rio de Janeiro: Forense,

Reforma das S.A. \& do mercado de capitais. Rio de Janeiro: Renovar, 1997. 
Os valores mobiliários na nova Lei das S/A. Revista de Direito Mercantil, Industrial, Econômico e Financeiro, São Paulo, nova série, v. 40, n. 124, p 72-79, out./dez. 2001 .

; GAAL, Ariádna B.; PARENTE, Flávia; HENRIQUES, Marcus de Freitas. Mercado de capitais: regime jurídico. 2. ed. rev. atual. Rio de Janeiro: Renovar, 2008.

ESPOSITO, Alexandre Siciliano. O setor elétrico brasileiro e o BNDES: reflexões sobre o financiamento aos investimentos e perspectivas. In: BNDES 60 anos: perspectivas setoriais. Out. 2012, p. 190-231. Disponível em: <http://www.bndes.gov.br>.

ESTADO Ltda. Época, São Paulo, n. 682, p. 64-70, jun. 2011.. Reportagem de José Fucs e Marcos Coronato.

FERRAZ JUNIOR, Tercio Sampaio. Direito e liberdade. In: Estudos de filosofia do direito: reflexões sobre o poder, a liberdade, a justiça e o direito. 3. ed. São Paulo: Atlas, 2009.

Estudos de filosofia do direito: reflexões sobre o poder, a liberdade, a justiça e o direito. 3. ed. São Paulo: Atlas, 2009.

As origens do Estado contemporâneo ou o Leviathan gestor da economia. Revista Brasileira de Filosofia, São Paulo v. 36, n. 148, p. 198-313, out./dez. 1987.

. O problema das lacunas e a filosofia de Miguel Reale. In: LAFER, Celso; FERRAZ JUNIOR, Tercio Sampaio. Direito política filosofia poesia: estudos em homenagem ao Professor Miguel Reale em seu octogésimo aniversário. São Paulo: Saraiva, 1992.

FILOMENO, José Geraldo Brito. Empresas de avaliação de riscos - ratings - e sua responsabilidade. In: KALANSKY, Daniel; PERIN JÚNIOR, Écio; PEYSER, Luis (Coords.). Direito empresarial: aspectos atuais de direito empresarial brasileiro e comparado. São Paulo: Método, 2005.

FINDLAW. SEC v. W. J. Howey Company. Disponível em: $<$ http://laws.findlaw.com/us/328/293.html>. Acesso em: 01 dez. 2005.

FISS, Owen. A burocratização do Poder Judiciário. In: Um novo processo civil: estudos norte-americanos sobre jurisdição, constituição e sociedade. Tradução de Daniel Porto Godinho da Silva e Melina de Medeiros Rós. São Paulo: Ed. Revista dos Tribunais, 2004. p. 163-203. 
FOCAULT, Michel. A governamentabilidade. In: - Microfisica do poder. Tradução de Roberto Machado. Rio de Janeiro: Graal, 2010. p. 277-193.

FORGIONI, Paula A. A evolução do direito comercial brasileiro: da mercancia ao mercado. 2. ed. rev. atual. ampl. São Paulo: Ed. Revista dos Tribunais, 2012.

. Os perfis do mercado. In: . A evolução do direito comercial brasileiro: da mercancia ao mercado. 2. ed. rev. atual. ampl. São Paulo: Ed. Revista dos Tribunais, 2012.

FRANÇA, Erasmo Valladão Azevedo e Novaes. Invalidade das deliberações de assembléia das SA. São Paulo: Malheiros Ed., 1999.

FRANCO, Vera Helena de Mello; SZTAJN, Rachel. Direito empresarial II. Sociedade anônima. Mercado de valores mobiliários. 2. ed. São Paulo: Ed. Revista dos Tribunais, 2009.

FRIEDMAN, Milton. The influence of the general theory. In: John Maynard Keynes. FRB Richmond Economic Quarterly, v. 83, n. 2, p. 1-23, Spring 1997. Disponível em: <http://ssm.com/abstract=2129832>. Acesso em: 15 jan. 2013.

John Maynard Keynes. FRB Richmond Economic Quarterly, v. 83, n. 2, p. 1-23, Spring 1997. Disponível em: <http://ssrn.com/abstract=2129832>. Acesso em: 15 jan. 2013.

FRONTINI, Paulo Salvador. Ação civil pública e separação dos poderes do Estado. In: MILARÉ, Edis (Coord.). Ação civil pública: Lei 7.537/1985 - 15 anos. São Paulo: Ed. Revista dos Tribunais, 2001.

- Ação civil pública em tutela de direitos difusos: condições da ação - indagações sobre a possibilidade jurídica do pedido, interesse processual e legitimidade dos efeitos jurídicos. In: MILARÉ, Edis (Coord.). A ação civil pública após 20 anos: efetividade e desafios. São Paulo: Ed. Revista dos Tribunais, 2005.

Cédula de crédito bancário. Revista de Direito Mercantil, Industrial, Econômico e Financeiro, São Paulo, nova série, n. 119, p. 52-67, 2000.

. A Comissão de Valores Mobiliários e a Lei 6.616/1978: uma charada processual! Revista de Direito Mercantil, Industrial, Econômico e Financeiro, São Paulo, nova série, n. 32, p. 103-105, 1978. 
Função social da companhia: limites do poder de controle. In: ADAMEK, Marcelo Vieira von (Coord.). Temas de direito societário e empresarial contemporâneos. São Paulo: Malheiros Ed., 2011. p. 533-551.

A governabilidade; questionamentos para além da política. Supremo Tribunal Federal, "Guarda da Constituição". Reflexões em tema de jurisdição voluntária. In: BENEVIDES, Maria Victoria de Mesquita; BERCOVICI, Gilberto; MELO, Claudinei de (Orgs.). Direitos humanos, democracia e república: homenagem a Fábio Konder Comparato. São Paulo: Quartier Latin, 2009. p. 873-888.

GALGANO, Francesco. Un diritto di classe per i mercanti politici della società comunale. In: . Lex mercatoria. Bologna: il Mulino, 2001.

Lex mercatoria. Bologna: il Mulino, 2001.

GILSON, Ronald J.; HANSMANN, Henry; PARGENDLER, Mariana. Regulatory dualism as a development strategy: corporate reform in Brazil, the U.S., and the EU. Stanford Law and Economics Olin Working Paper. n. 390, Mar. 2010. Disponível em: $<\mathrm{http}: / /$ ssrn.com/abstract $=1541226>$ or $<\mathrm{http}: / \mathrm{dx}$.doi.org/10.2139/ssrn.1541226>. Acesso em 15. mar. 2013.

GOLDBERG, Daniel Krepel. A Lei 10.303, de 2001, e a inclusão dos derivativos no rol, dos valores mobiliários. Revista de Direito Mercantil, Industrial, Econômico e Financeiro, São Paulo, nova série, v. 42, n. 129, p. 73-82, jan./mar. 2003.

GRAU, Eros Roberto. Comentário: o Estado e a ordem econômica segundo Themístocles Cavalcanti, 60 anos depois. Revista dos Tribunais, São Paulo, v. 101, n. 922, p. 47-51, ago. 2012.

. Crítica e defesa da legalidade. In: O direito posto e o direito pressuposto.

8. rev. ampl. São Paulo: Malheiros Ed., 2011.

Crítica da discricionariedade e restauração da legalidade e crítica da separação dos poderes: as funções estatais, os regulamentos e a legalidade no direito brasileiro, as leis-medida. In: . $O$ direito posto e o direito pressuposto. 8. rev. ampl. São Paulo: Malheiros Ed., 2011.p. 189-251.

Crítica da "Separação dos Poderes". In: $O$ direito posto e o direito pressuposto. 8. rev. ampl. São Paulo: Malheiros Ed., 2011. 
- O direito do modo de produção capitalista e a teoria da regulação. In: 0 direito posto e o direito pressuposto. 8. rev. ampl. São Paulo: Malheiros Ed., 2011. p. 116144.

. O direito posto e o direito pressuposto. 8. rev. ampl. São Paulo: Malheiros Ed., 2011.

. As formas de atuação do Estado em relação ao processo econômico: a noção de atividade econômica: o direito econômico. In: A Ordem Econômica na Constituição de 1988. 14. ed. rev. atual. São Paulo: Malheiros Ed., 2010.

. Lucratividade e função social nas empresas sob o controle do Estado. . Revista de Direito Mercantil, Industrial, Econômico e Financeiro, São Paulo, nova série, n. 55, p. 35$59,1984$.

. Os modelos de direito forma e de direito moderno e a dupla desestruturação do direito. In: $O$ direito posto e o direito pressuposto. 8. rev. ampl. São Paulo: Malheiros Ed., 2011. p. 93-115.

. Modo de regulação capitalista e regulação. In: . $O$ direito posto e o direito pressuposto. 8. rev. ampl. São Paulo: Malheiros Ed., 2011. p. 116-125.

. Nota introdutória sobre o direito. In: $O$ direito posto $e$ o direito pressuposto. 8. rev. ampl. São Paulo: Malheiros Ed., 2011.

. A Ordem Econômica na Constituição de 1988. 14. ed. rev. atual. São Paulo: Malheiros Ed., 2010.

; FORGIONI, Paula A. Ato administrativo: características e presunção de legitimidade. Ausência de competência do CDE para apreciar os atos administrativos praticados pelo BACEN no âmbito de processo de liquidação extrajudicial. In: GRAU, Eros Roberto; FORGIONI, Paula A. (Orgs.). O Estado, a empresa e o contrato. São Paulo: Malheiros Ed., 2005. p. 210-227.

HANSMANN, Henry; KRAAKMAN, Reinier H.; SQUIRE, Richard C. Law and the Rise of the Firm. ECGI - Law Working Paper, n. 57/2006, 2006. Disponível em: $<$ http://ssrn.com/abstract=873507>. Acesso em: 19 dez. 2007.

HAYEK, Friedrich A. The use of knowledge in society. American Economic Review, v. 35, n. 4.4 p. 519-530, 1945. Disponível em: <http://www.econlib.org/library/Essays/hykKnw.html>. Acesso em: 15 jan. 2013. 
HESSE, Konrad. A força normativa da Constituição. Tradução de Gilmar Ferreira Mendes. Porto Alegre: Sergio Fabris, 1991.

HULL, John. Introdução aos mercados futuros e de opções. São Paulo: Cultura; Bolsa de Mercadorias \& Futuros, 1995.

IPEA. Comunicados do IPEA, n. 83, mar. 2011. Disponível em: <http:/www.ipea.gov.br/portal/images/stories/PDFs/comunicado/110331_comunicadoipea 83.pdf $\geq$ acesso: 09 out. 2012.

KAPLAN, Abrahan; LASWELL, Harold. Poder e sociedade. Trad. de Maria Lucy Gurgel Valente de Seixas Corrêa. Brasília-DF: Ed. da Universidade de Brasília, 1979.

KELSEN, Hans. Teoria pura do direito. Tradução de João Batista Machado. São Paulo: Martins Fontes, 1995.

KNIGHT, Frank H. Risk, uncertainty, and profit. Boston MA: Hart, Schaffner and Marx; Houghton Mifflin, 1921. Disponível em: <http:/oll.libertyfund.org/title/306>. Acesso em: 15 jan. 2013.

Structure and methods for meeting uncertainty. In: Risk, uncertainty, and profit. Boston MA: Hart, Schaffner and Marx; Houghton Mifflin, 1921. Disponível em: <http://oll.libertyfund.org/title/306>. Acesso em: 15 jan. 2013.

LAMY FILHO, Alfredo; PEDREIRA, José Luiz Bulhões. 2. ed. A Lei das S.A.: pressupostos. Elaboração. Rio de Janeiro: Renovar, 1995. v. 1.

LAW OFFICES OF HOWARD G. SMITH. Press release. Complaint. Disponivel em: $<$ http://www.howardsmithlaw.com/Cases/Sadia.html>. Acesso em: 14 nov. 2008.

LEÃES, Luis Gastão Paes de Barros. O conceito de "security" no direito norte-americano e o conceito análogo no direito brasileiro. Revista de Direito Mercantil, Industrial, Econômico e Financeiro, São Paulo, nova série, n. 14, p. 41-60, 1974.

Estado intervencionista e sociedade civil. In: Mercado de capitais \& insider trading. São Paulo: Ed. Revista dos Tribunais, 1982.

A estrutura normativa do mercado de capitais. In: Mercado de capitais \& insider trading. São Paulo: Ed. Revista dos Tribunais, 1982. 
. Mercado de capitais \& insider trading. São Paulo: Ed. Revista dos Tribunais, 1982.

LOSS, Louis. Securities regulation. Boston; Toronto: Little Brown and Company, 1961.

; SELIGMAN, Joel. Fundamentals of securities regulation. New York: Aspen, 2001.

MANCUSO, Rodolfo de Camargo. Interesses difusos: conceito e legitimação para agir. 6. ed. rev. atual. ampl., São Paulo: Ed. Revista dos Tribunais, 2000.

MARQUES NETO, Floriano de Azevedo. Limites à abrangência e à intensidade da regulação estatal. Revista de Direito Público da Economia, Belo Horizonte, v. n. 1, p. 6992, jan./mar. 2003.

. A nova regulação estatal e as agências independentes. In: SUNDFELD, Carlos Ari (Coord.). Direito administrativo econômico. São Paulo: Malheiros Ed., 2000. p. 72-98.

MATTOS, Paulo (Coord.); PRADO, Mariana Mota; ROCHA, Jean Paul Cabral Veiga da; COUTINHO, Diogo R.; OLIVA, Rafael (Orgs.). Regulação econômica e democracia: o debate norte-americano. São Paulo: Ed. 34, 2004.

MATTOS FILHO, Ary Oswaldo. O conceito de valor mobiliário. Revista de Direito Mercantil, Industrial, Econômico e Financeiro, São Paulo, nova série, v. 24, n. 59, p. 3055 , jul./set. 1985 .

MELLO, Oswaldo Aranha Bandeira de. Princípios gerais de direito administrativo. 3. ed. São Paulo: Malheiros Ed., 2007. v. 1.

MINISTÉRIO DA FAZENDA. Disponivel em:<http:www.fazenda.gov.br $>$. Acesso em: 08 jan. 2013.

MINISTÉRIO DE MINAS E ENERGIA. Geração, transmissão e distribuição de energia elétrica: perguntas e respostas. Disponível em: <www.mme.gov.br>.

. Portaria 578. 31 out. 2012. Disponível em: <www.mme.gov.br>.

\footnotetext{
MINISTERIO DO PLANEJAMENTO ORÇAMENTO E GESTÃO. Substitutivo ao Projeto de Lei 3.337/2004. Disponível em <http://www.planejamento.gov.br/secretarias/upload/Arquivos/seges/regulacao/legislacao/ 081021_REG_Leg_substitutivo.pdf $>$. Acesso em: 09 jan. 20.
} 
MOREIRA, Egon Bockmann. Conselho Monetário Nacional, Banco Central do Brasil e Comissão de Valores Mobiliários. Considerações acerca de sua natureza jurídica em face das chamadas 'agências administrativas'. Revista Trimestral de Direito Público, São Paulo, n. 25, p. 185-217, 1999.

MOREIRA NETO, Diogo de Figueiredo. Direito regulatório. Rio de Janeiro: Renovar, 2003 .

MUNHOZ, Eduardo Secchi. Empresa contemporânea e direito societário: poder de controle e grupos de sociedades. São Paulo: Juarez de Oliveira, 2002.

NORTH, Douglass C. Institutions, transaction costs, and the rise of merchant empires. In: TRACY, James D. (Ed.) The political economy of merchant empires. Cambridge: Cambridge University Press, 1997. p. 22-40.

OXERA CONSULTING LTD. What would be the costs and benefits of changing the competitive structure of the market for trading and post-trading services in Brazil? Relatório elaborado a pedido da Comissao de Valores Mobiliarios. Disponivel em: <http://www.cvm.gov.br/port/Public/publ/Oxera\%20report\%2018062012.pdf>.

PARGENDLER, Mariana. The unintended consequences of state ownership: the Brazilian experience. Theoretical Inquiries in Law, v. 13, n. 2, 1 out. 2012. Disponível em: $<$ http://ssrn.com/abstract=1939945>. Acesso em: 15 mar. 2013.

PAULANI, Leda M. Hayek e o individualismo no discurso econômico. Lua Nova, São Paulo, v. 38, p. 97-124, 1996.

PINTO JUNIOR, Mario Engler. Empresa Estatal: função econômica e dilemas societários. São Paulo: Atlas, 2010.

A POPULARIZAÇÃO do mercado de capitais. RT Informa, São Paulo, ano 8, n. 50, p. 45, jul./ago. 2007.

POSNER, Richard A. Teoria da regulação econômica. Tradução de Mariana Mota Prado. In: MATTOS, Paulo (Coord.); PRADO, Mariana Mota; ROCHA, Jean Paul Cabral Veiga da; COUTINHO, Diogo R.; OLIVA, Rafael (Orgs.). Regulação econômica e democracia: o debate norte-americano. São Paulo: Ed. 34, 2004.

PRADO, Mariana Mota. Accountability mismatch: as agências reguladoras independentes e o Governo Lula. In: BINENBOJM, Gustavo (Coord.). Agências reguladoras e democracia. Rio de Janeiro: Lumen Juris, 2006. p. 225-251. 
PRESIDÊNCIA DA REPÚBLICA DO BRASIL. Exposição de Motivos Interministerial $n^{\circ}$ 37/MME/MF/AGU. 11 set. 2012.

. Exposição de Motivos Interministerial nº 0050-A/MME/MF/AGU. 29 nov. 2012.

PROENÇA, José Marcelo Martins. Insider trading. regime jurídico do uso de informações privilegiadas no mercado de capitais. São Paulo: Quartier Latin, 2005.

PUNSUVO, Fabio Riberi; KAYO, Eduardo Kazuo; BARROS, Lucas Ayres Barreira de Campos. O ativismo dos fundos de pensão e a qualidade da governança corporativa. Revista de Contabilidade Financeira, Universidade de São Paulo, v. 18, n. 45, p. 63-72, set./dez. 2002.

REALE, Miguel. Estudos de filosofia e ciência do direito. São Paulo: Saraiva, 1978. . Pluralismo e liberdade. Rio de Janeiro: Expressão e Cultura, 1998. . Teoria do direito e do Estado. 5. ed. São Paulo: Saraiva, 2000.

RIPERT, Georges. Aspectos jurídicos do capitalismo moderno. Trad. de Gilda G. de Azevedo. Rio de Janeiro: Freitas Bastos, 1947.

SALOMÃO FILHO, Calixto. Função social do contrato: primeiras anotações. Revista de Direito Mercantil, Industrial, Econômico e Financeiro, São Paulo, nova série, n. 132, p. 724, 2003.

. O novo direito societário. 2. ed. São Paulo: Malheiros Ed., 2002.

O novo direito societário. 3. ed. rev. e ampl., São Paulo: Malheiros Ed., 2006.

. Poder econômico: a marcha da aceitação. In: COMPARATO, Fábio Konder; SALOMÃO FILHO, Calixto. O poder de controle na sociedade anônima. 4. ed. Rio de Janeiro: Forense, 2005.

Regulação da atividade econômica: (princípios e fundamentos jurídicos). 2. ed. rev. e ampl. São Paulo: Malheiros Ed., 2008.

Regulação, desenvolvimento e meio ambiente. regulamentação da atividade empresarial para o desenvolvimento. In: SALOMÃO FILHO, Calixto (Coord.). Regulação e desenvolvimento: novos temas. São Paulo: Malheiros Ed., 2012. p. 15-73.

Regulação e desenvolvimento: novos temas. São Paulo: Malheiros Ed., 2012. 
Sociedade anônima: interesse público e privado. Revista de Direito Mercantil, Industrial, Econômico e Financeiro, São Paulo, nova série, n. 127, p. 7-20, 2002.

SARLET, Ingo Wolfgang. Perspectiva histórica: dos direitos naturais do homem aos direito fundamentais constitucionais e a problemática das assim denominadas dimensões dos direito fundamentais. In: $A$ eficácia dos direitos fundamentais: uma teoria dos direitos fundamentais na perspectiva constitucional. 10. ed. rev. atual. e ampl. Porto Alegre: Livr. do Advogado Ed., 2009.

SHAPIRO, Mario Gomes. Novos parâmetros para a intervenção do Estado na economia: persistência e dinâmica na atuação do BNDES em uma economia baseada no conhecimento. 2009. Tese (Doutorado) - Faculdade de Direito da Universidade de São Paulo, São Paulo, 2009.

A regulação institucional no sistema financeiro: a atuação do BNDES no financiamento do desenvolvimentismo. In: . Novos parâmetros para a intervenção do Estado na economia: persistência e dinâmica na atuação do BNDES em uma economia baseada no conhecimento. 2009. Tese (Doutorado) - Faculdade de Direito da Universidade de São Paulo, São Paulo, 2009.

SILVA, José Afonso da. Curso de direito constitucional positivo. 20. ed. rev. atual. nos termos da Reforma Constitucional até a EC 35/01. São Paulo: Malheiros Ed., 2002.

SOUZA JUNIOR, Francisco Satiro. Agências de classificação de créditos e seu papel de gatekeepers. In: ADAMEK, Marcelo Vieira von (Coord.). Temas de direito societário e empresarial contemporâneos. São Paulo: Malheiros Ed., 2011.p. 373-387.

STIGLER, George J. A teoria da regulação econômica. Tradução de Emerson Fabiani. In: MATTOS, Paulo (Coord.); PRADO, Mariana Mota; ROCHA, Jean Paul Cabral Veiga da; COUTINHO, Diogo R.; OLIVA, Rafael (Orgs.). Regulação econômica e democracia: o debate norte-americano. São Paulo: Ed. 34, 2004.

STUBER, Walter Douglas. A "contabilidade criativa" e o cumprimento da meta fiscal. Conteúdo Jurídico, Brasília-DF: 16 jan. 2013. Disponível em: $<$ http://www.conteudojuridico.com.br/?colunas\&colunista=69_\&ver=1446>. Acesso em: 19 mar. 2013. 
SUNDFELD, Carlos Ari. Introdução às agências reguladoras. a participação privada nas empresas estatais. In: SUNDFELD, Carlos Ari (Coord.). Direito administrativo econômico. São Paulo: Malheiros Ed., 2000. p. 17-38 e 264-285.

SUPREMO TRIBUNAL FEDERAL. Disponível em: <http://www.stf.gov.br>. Acesso em: 22 jun. 2010.

SZTAJN, Rachel. Regulação e mercado de valores mobiliários. Revista de Direito Mercantil, Industrial, Econômico e Financeiro, São Paulo, v.43, n. 135, p. 136-147, jul./set. 2004.

TRIBUNAL DE CONTAS DA UNIÃO. Disponível em: <http://contas.tcu.gov.br/>. Acesso em: 21 jan. 2013.

TRIBUNAL REGIONAL FEDERAL DA 2a REGIÃO. Disponível em: $<$ http://www.trf2.jus.br>.

TRIBUNAL REGIONAL FEDERAL DA $3^{\mathrm{a}}$ REGIÃO. Disponível em: $<$ http://www.trf3.jus.br>.

TURCZYN, Sidnei. O sistema financeiro nacional e a regulação bancária. São Paulo: Ed. Revista dos Tribunais, 2005.

VALVERDE, Trajano de Miranda. Sociedade por ações: comentários ao Decreto-lei $\mathrm{n}^{\circ}$ 2.627, de 26 de setembro de 1940: arts. $1^{\circ}$ a 73 . Ed. rev. e atual. Rio de Janeiro: Forense, 1959.

VENÂNCIO FILHO, Alberto. A intervenção do Estado no domínio econômico. Rio de Janeiro: Fundação Getúlio Vargas, 1968.

WALD, Arnoldo. O mercado futuro de índices e os valores mobiliários. Revista de Direito Mercantil, Industrial, Econômico e Financeiro, São Paulo, nova série, n. 57, p. 5-18, 1985.

WEBER, Max. Economia e sociedade: fundamentos da sociologia compreensiva. Trad. de Regis Barbosa e Karen Elsabe Barbosa; rev. téc. de Gabriel Cohn. 4. ed. Reimpr. Brasília: Ed. da Universidade de Brasília, 2009. v. 1.

WIEDEMANN, Herbert. Excerto do "Direito societário I: fundamentos". Trad. de Erasmo Valladão Azevedo e Novaes França. In: FRANCA, Erasmo Valladão Azevedo e Novaes (Coord.). Direito societário contemporâneo I. São Paulo: Quartier Latin, 2009. p. 11-24. 
YAZBEK, Otavio. Regulação do mercado financeiro e de capitais. Rio de Janeiro: Elsevier, 2007.

Regulação do mercado financeiro e de capitais. 2. ed. ampl. Rio de Janeiro: Elsevier, 2008.

A teoria econômica neoclássica como ponto de partida. In: Regulação do mercado financeiro e de capitais. 2. ed. ampl. Rio de Janeiro: Elsevier, 2008. 